University of Wollongong

Research Online

Faculty of Engineering and Information

Faculty of Engineering and Information

Sciences - Papers: Part A

Sciences

$1-1-2012$

\title{
Voltage security constrained reactive power optimization incorporating wind generation
}

\author{
L G. Meegahapola \\ University of Wollongong, lasantha.meegahapola@rmit.edu.au \\ E Vittal \\ University College Dublin, eknath.vittal@ucd.ie \\ A Keane \\ University College Dublin, andrew.keane@ucd.ie \\ D Flynn \\ University College Dublin
}

Follow this and additional works at: https://ro.uow.edu.au/eispapers

Part of the Engineering Commons, and the Science and Technology Studies Commons

Research Online is the open access institutional repository for the University of Wollongong. For further information contact the UOW Library: research-pubs@uow.edu.au 


\title{
Voltage security constrained reactive power optimization incorporating wind generation
}

\author{
Abstract \\ This paper presents a comparative analysis between conventional optimal power flow (OPF) and voltage \\ constrained OPF strategies with wind generation. The study has been performed using the New England \\ 39 bus system with 12 doublyfed induction generator (DFIG) based wind farms installed across the \\ network. A voltage security assessment is carried out to determine the critical wind farms for voltage \\ stability enhancement. The power losses and individual wind farm reactive power generation have been \\ compared with and without voltage stability constraints imposed on the OPF simulation. It is shown that \\ voltage constrained OPF leads to much greater active power losses in the network. Furthermore, the \\ reactive power contribution of each wind farm is determined and a selective optimization completed to \\ evaluate individual wind farm contributions towards system active power losses. Moreover, number of \\ reactive power optimized wind farms can be reduced by only using those wind farms which contribute \\ least to system active power losses. In addition, selective voltage constrained OPF can also be performed \\ to minimize the adverse effect on system losses. Ultimately, the system operator should select the \\ optimal wind farms for both voltage stability and loss minimization considering the trade-off between \\ energy savings and voltage security.
}

\section{Keywords}

security, constrained, reactive, power, optimization, voltage, incorporating, generation, wind

\section{Disciplines}

Engineering | Science and Technology Studies

\section{Publication Details}

L. G. Meegahapola, E. Vittal, A. Keane \& D. Flynn, "Voltage security constrained reactive power optimization incorporating wind generation," in IEEE International Conference on Power System Technology (POWERCON), 2012, pp. 1-6. 


\title{
Voltage Security Constrained Reactive Power Optimization Incorporating Wind Generation
}

\author{
L.G. Meegahapola, Member, IEEE, and E. Vittal, Member, IEEE, A. Keane, Member, IEEE, \\ D. Flynn, Senior Member, IEEE
}

\begin{abstract}
This paper presents a comparative analysis between conventional optimal power flow (OPF) and voltage constrained OPF strategies with wind generation. The study has been performed using the New England 39 bus system with 12 doublyfed induction generator (DFIG) based wind farms installed across the network. A voltage security assessment is carried out to determine the critical wind farms for voltage stability enhancement. The power losses and individual wind farm reactive power generation have been compared with and without voltage stability constraints imposed on the OPF simulation. It is shown that voltage constrained OPF leads to much greater active power losses in the network. Furthermore, the reactive power contribution of each wind farm is determined and a selective optimization completed to evaluate individual wind farm contributions towards system active power losses. Moreover, number of reactive power optimized wind farms can be reduced by only using those wind farms which contribute least to system active power losses. In addition, selective voltage constrained OPF can also be performed to minimize the adverse effect on system losses. Ultimately, the system operator should select the optimal wind farms for both voltage stability and loss minimization considering the trade-off between energy savings and voltage security.
\end{abstract}

Index Terms- doubly-fed induction generator (DFIG), loss minimization, Prony analysis, reactive power optimization, voltage security.

\section{INTRODUCTION}

$\mathrm{V}$ OLTAGE security and reactive power are two major concerns for renewable energy dominant power networks. An inability to meet reactive power demand will result in additional active power losses and voltage security may be threatened due to inadequate voltage control mechanisms in the power networks. However, both voltage and reactive power are interrelated; therefore maximization of one objective may result in an adverse impact on the other. In terms of wind generation, most power electronics based wind generators (e.g. doubly-fed induction generator (DFIG), fullconverter wind generator (FCWG)) offer control flexibility over their reactive power generation, and these generators possess considerable reactive power capability within their generator and converter system. In the published literature wind farm reactive power capability is utilized to minimize losses in the transmission system [1-2]. This is achieved by

Lasantha Meegahapola is with the Endeavour Energy Power Quality and Reliability Centre, University of Wollongong, Wollongong, 2500, Australia. (e-mail: lasantha@uow.edu.au).

Eknath Vittal, Andrew Keane and Damian Flynn are with the University College Dublin, Ireland (e-mail addresses: eknath.vittal@ucd.ie, andrew.keane@ucd.ie,damian.flynn@ucd.ie). optimal power flow (OPF) analysis constrained to network capability and grid-codes [1].

A number of studies have been published on security constrained OPF methods [3-8]. In these research studies the voltage stability and other security constraints are employed within the optimization algorithm using security indices, hence influence of individual generators on system security haven't explicitly considered. In addition, these studies are limited to conventional power networks without any wind generation. Moreover, a number of OPF studies have been performed with wind generation [1-2], however in these studies voltage security constraints haven't been explicitly considered within the optimization algorithm.

The wind farms used in this study are based on DFIGs and they can be operated either in voltage control or power factor control mode. In the terminal voltage control strategy, reactive power production is controlled to achieve a target voltage at the designated bus, while for fixed power factor control reactive power is produced in proportion to the active power output. In systems with high penetrations of wind generation, voltage security is also a critical issue that must be addressed. Since wind generation is highly variable, application of reactive power control from the wind farms can play an important role in improving system voltage security [9].

In this presented study critical wind farms are screened considering their participation factor to determine the wind farms which require voltage control strategy in order to improve voltage stability. Comparative analysis is then conducted between conventional OPF and voltage constrained OPF methods, critically analyzing the reactive power dispatch and network active power losses. Finally, selective optimization is carried out in order to determine the most suitable wind farms for optimization.

This paper is structured as follows: the optimization algorithm and network configuration are described in Section II. Voltage security assessment for wind farms is presented in Section III. A comparative analysis between conventional OPF and voltage security constrained OPF is presented in Section IV. In section V selective optimization is carried out to determine the wind farms with significant contribution to system loss reduction. Discussion and conclusions are presented in Section VI and VII respectively.

\section{OPTIMIZATION ALGORITHM AND NETWORK CONFIGURATION}

\section{A. Optimal Power Flow for Loss Minimization}

The main objective of OPF is to utilize the reactive power capability of the DFIG wind farms for system active power 
loss minimization. The objective here is to minimize the active power loss in the network, subject to the following objective function for loss minimization.

$$
F=\sum_{\substack{k \in N_{b} \\ k=(i, j)}} g_{k}\left(V_{i}^{2}+V_{j}^{2}-2 V_{i} V_{j} \cos \theta_{i j}\right)
$$

where, $V_{i}, V_{j} g_{k}, N_{b}$, and $\theta_{i j}$ denote the voltage at bus $i$, the voltage at bus $j$, the conductance of branch $k$, the number of branches in the system, and the voltage angle difference between bus $i$ and bus $j$ respectively. Regardless of the objective function, however, an OPF must ensure that the entire set of voltage and power constraints are satisfied. Various categories of constraints exist, and these distinct categories are described below.

\section{1) Equality constraints}

The transmission network is modelled by a power balance equation at each node. The algebraic sum of the active and reactive powers injected into each node $i$ must equal zero:

$$
\begin{aligned}
& P_{i}-V_{i} \sum_{j=1}^{N_{B}} V_{j}\left(G_{i j} \cos \theta_{i j}+B_{i j} \sin \theta_{i j}\right)=0 \\
& Q_{i}-V_{i} \sum_{j=1}^{N_{B}} V_{j}\left(G_{i j} \cos \theta_{i j}-B_{i j} \sin \theta_{i j}\right)=0, \quad i \in N_{B}
\end{aligned}
$$

where $P_{i}, Q_{i}, N_{B}, G_{i j}$, and $B_{i j}$ denote the active power injected at bus $i$, the reactive power injection at bus $i$, the number of buses in the system, the mutual conductance between bus $i$ and bus $j$, and the mutual susceptance between bus $i$ and bus $j$ respectively. Each wind farm's active power output is also considered to be at a fixed value for a specific wind condition during the optimization process.

$$
\sum_{i=1}^{N_{W}} P_{W G_{i}}=P_{\text {wind }}, i \in N_{W}
$$

where $P_{W G i}, P_{\text {wind }}$ and $N_{W}$ denote the active power output of wind farm $i$, the total wind power generation, and the total number of wind farms in the system respectively.

\section{2) Inequality constraints}

The DFIG reactive power output $\left(Q_{D F I G}\right)$ can be controlled, and the following inequality constraint can be included within the OPF framework. The DFIG reactive power capability $\left(Q_{D F I G i}\right)$ for a power factor range of 0.95 leading to 0.95 lagging can be expressed as follows:

$$
-0.328 \mathrm{pu} \leq Q_{D F I G_{i}} \leq 0.328 \mathrm{pu}, i \in N_{W}
$$

The conventional generating units have maximum and minimum generating limits, both for real and reactive power, beyond which it is not feasible to generate for technical or economic reasons.

$$
\begin{aligned}
P_{g_{i}}^{\min } & \leq P_{g_{i}} \leq P_{g_{i}}^{\max } \\
Q_{g_{i}}^{\min } & \leq Q_{g_{i}} \leq Q_{g_{i}}^{\max } \quad i \in N_{G}
\end{aligned}
$$

where $P_{g i}{ }^{{ }^{i n}}, P_{g i}{ }^{{ }^{a x}} Q_{g i}{ }^{\text {min }}$, and $Q_{g i}{ }^{{ }^{a x}}$ denote the minimum and maximum active power limits of the generator at bus $i$, and the minimum and maximum reactive power limits of the generator at bus $i$ respectively. Voltage limits constrain bus voltages $\left(V_{i}\right)$ to remain within an allowable range. Our assumption here is that node voltages are maintained between 0.95 and $1.05 \mathrm{pu}$.

$0.95 \mathrm{pu} \leq V_{i} \leq 1.05 \mathrm{pu}, i \in N_{B}$

The formulated OPF problem was then solved using the optimal power flow facility of DIgSILENT Power Factory [10].

\section{B. Network Configuration}

The New England 39 bus system was modified by introducing DFIG based wind farms across the network while creating wind-rich high demand regions. The wind farm locations were chosen based on their proximity to synchronous generation and system loads as illustrated in Fig. 1.

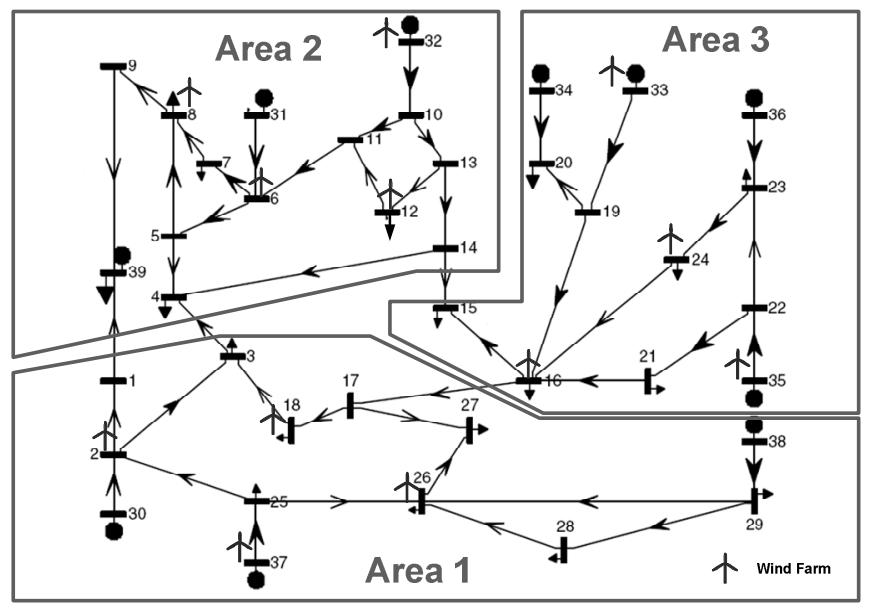

Fig. 1. New England 39 test system

There are 12 wind farms installed in the test system. For each case the maximum capacity of the farm was varied to create different penetration levels in the system. In the first case, the installed capacity of each of the 12 farms was 50 MW resulting in a penetration level of $10.4 \%(600 \mathrm{MW})$. The second case had a penetration of $20.7 \%(1,200 \mathrm{MW})$ with farms of $100 \mathrm{MW}$ installed capacity. Finally, the last case had a penetration of $31.1 \%(1800 \mathrm{MW})$ with farms having a capacity of 150 MW each. The New England 39 bus system was adopted as the test network for this study with 12 DFIG based wind farms installed across the network. Each individual wind farm is capable of delivering $150 \mathrm{MW}$ active power output with an assumed (49.2 MVAr) $\pm 0.328 \mathrm{pu}$ reactive power capability across its operating range.

\section{VOLTAGE SECURITY ASSESSMENT}

The voltage security assessment was conducted using the DSATools simulation package [11]. In order to identify the critical wind farm locations from a voltage stability perspective a small-signal analysis was conducted for the New England 39 bus system. However, DFIGs are mechanically decoupled from the power system; therefore a new methodology was developed in order to carry out the small-signal stability study. In this methodology wind farms are initially modelled as conventional synchronous generators 
with excitation systems, governors, and stabilizers, identified as synchronous wind farms. Following this, a small-signal analysis is completed and the participation factors of the synchronous wind farms are identified for varying system conditions. The analysed system scenarios are listed in Table I.

Table I: System Scenarios for Small-Signal Analysis

\begin{tabular}{c|c|c|c|c}
\hline \hline Scenario & A & B & C & D \\
\hline $\begin{array}{c}\text { Wind } \\
\text { Generation }\end{array}$ & $2400 \mathrm{MW}$ & $2400 \mathrm{MW}$ & $1200 \mathrm{MW}$ & $1200 \mathrm{MW}$ \\
\hline Load & $5811 \mathrm{MW}$ & $6811 \mathrm{MW}$ & $5811 \mathrm{MW}$ & $6811 \mathrm{MW}$ \\
\hline \hline
\end{tabular}

Each of the original ten synchronous units in the New England 39 bust test system was individually displaced in order to represent different initial dispatch conditions. The modes of the nine original units that remained online were examined and the participation factors that belonged to the synchronous wind farms were recorded. Over the four scenarios, the participation factors of the synchronous wind farms were averaged and those farms that displayed consistently high participation factors were deemed to be critical. The average participation factors are shown in Fig. 2.

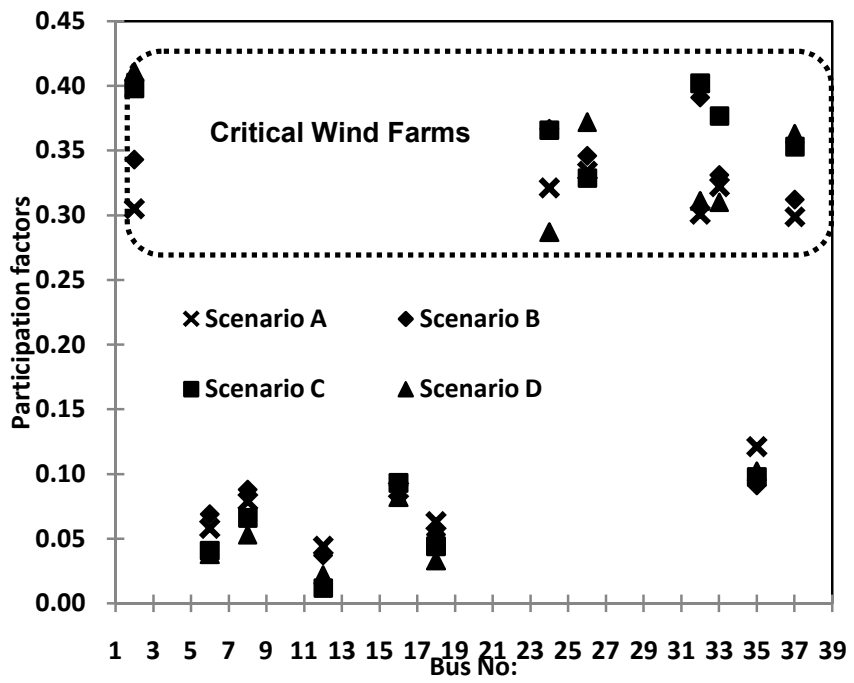

Fig. 2. Recorded participation factors for wind farms

According to Fig. 2 wind farms installed at buses 2, 24, 26, 32, 33 and 37 indicate high participation factors (i.e. participation factors above 0.1) despite different wind and load conditions; and hence they were regarded as critical wind farms for stability enhancement. Therefore, they should be operated in a voltage control mode for voltage stability enhancement.

In order to validate the above outcome the synchronous generators at the wind farm locations were replaced with DFIGs. Those farms that were identified as critical had terminal voltage control implemented, while the remaining farms were operated using a fixed power factor control scheme at 0.95 capacitive. This control configuration was called the critical control case. To confirm the effectiveness of the critical control case, a transient simulation was also completed. The transient simulation was carried out for Scenario A. Here, the critical control case was compared to a scenario where all of the wind farms were modelled as DFIGs with full terminal voltage control enabled, known as the full control case. The rotor angle traces of the generator at bus 34 following the loss of the generator at bus 32 is given in Fig. 3 .

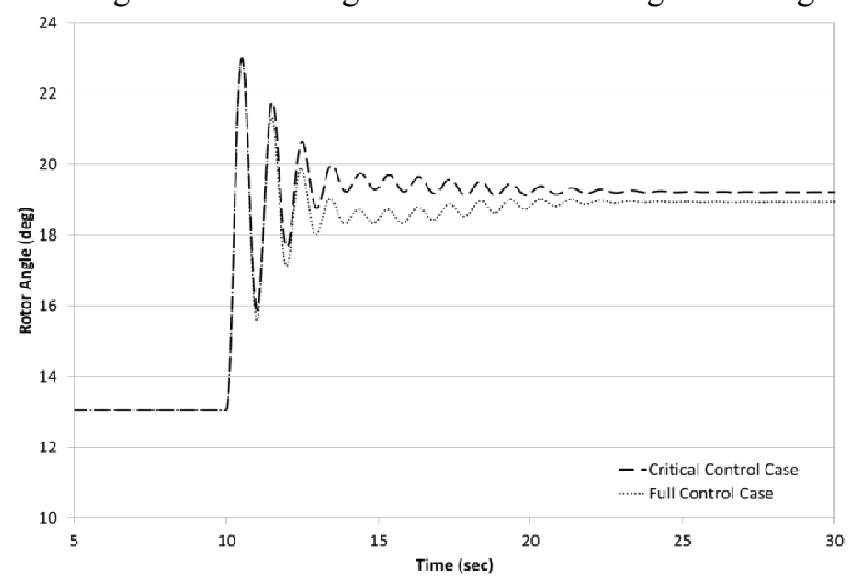

Fig. 3. Rotor angle traces for the generator at bus 34 following the loss of the generator at bus 32

From Fig. 3 it can be seen that the two control strategies illustrate the same behaviour following the disturbance. To further investigate the two control conditions Prony analysis was carried out and Table II illustrates the results.

Table II: Prony Analysis Results for both Control Cases

\begin{tabular}{c|c|c|c}
\hline \hline \multicolumn{4}{c}{ Critical Control Case } \\
\hline Magnitude & Phase & Frequency (Hz) & Damping (\%) \\
\hline 3.43 & $178.6^{\circ}$ & 1.010 & 6.44 \\
\hline 1.47 & $151.4^{\circ}$ & 0.918 & 6.20 \\
\hline \multicolumn{4}{c}{ Full Control Case } \\
\hline 2.87 & $184.4^{\circ}$ & 1.010 & 6.29 \\
\hline 1.46 & $153.9^{\circ}$ & 0.918 & 6.30 \\
\hline \hline
\end{tabular}

According to Table II it is further evident that both control conditions illustrate the same characteristics, and thus it confirms the validity of the methodology used for voltage security assessment.

\section{Comparative Analysis Between CONVEntional OPF AND VOLTAGE CONSTRAINED OPF}

\section{A. Optimization Strategies}

Two optimization strategies were developed in order to investigate the influence of voltage security constraints on system loss minimization. Therefore, following two strategies have been analyzed:

\section{- Strategy 1}

Reactive power was optimized at twelve wind farms with the objective of minimizing the system losses. The bus voltages were maintained between $0.95 \mathrm{pu}$ to $1.05 \mathrm{pu}$, with an assumed \pm 0.328 pu reactive power capability for each DFIG wind farm during optimization.

\section{- Strategy 2:}

Optimization was carried out to minimise system losses with voltage constraints applied at certain wind farms to maintain voltage stability in the network based on the conclusions drawn from the voltage stability study. Therefore, the bus voltages for the wind farms sited at buses 2, 24, 26, 32,33 , and 37 were maintained at a constant value during the optimization. The remaining wind farms were optimised 
based on the reactive power capability and voltage limits outlined in strategy 1.

\section{B. Comparison of Losses}

It is assumed that all the wind farms experience the same wind conditions; and hence generate the same active power output. The system load was assumed to be constant throughout the simulation. The variation in system losses with wind farm active power output for both scenarios is illustrated in Fig. 4.

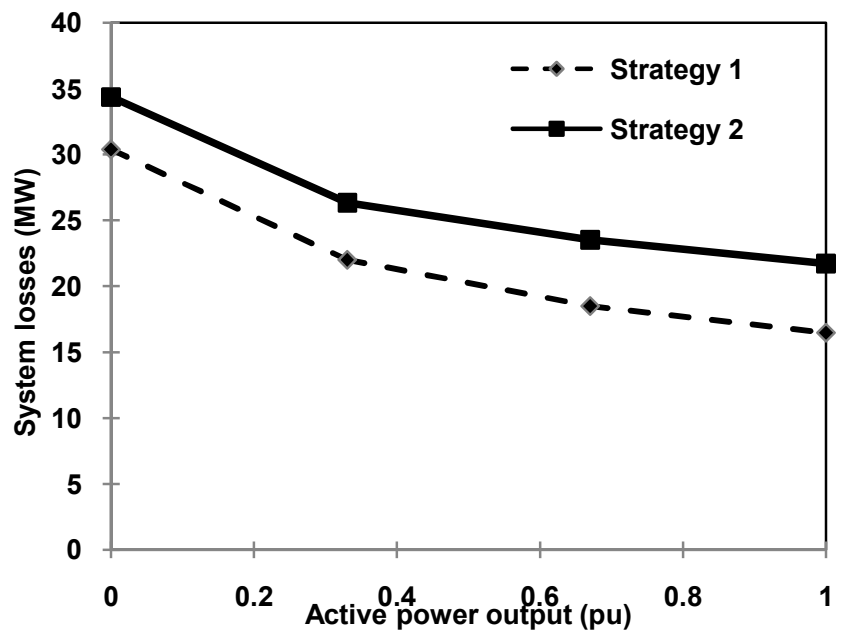

Fig. 4: Active power loss variation with wind farm power output

According to Fig. 4, when wind farms are operated in voltage control mode the active power losses have increased from $13 \%$ to $31 \%$ when the wind farms power output increases from $0 \mathrm{pu}$ to $1 \mathrm{pu}$. Therefore, strategy 2 indicates a significant increase in active power losses in the network. The trend in system active power loss reduction remains the same for both strategies despite differences in their minimum active power losses in the system. The average reactive power dispatch as a percentage of total reactive power capability can be expressed as follows:

Reactive Power Contribution $=\left|\frac{Q_{d i s}}{Q_{\text {cap }}}\right|$

The reactive power contribution from the wind farms for strategy 1 was calculated according to (7) and illustrated in Fig. 5.

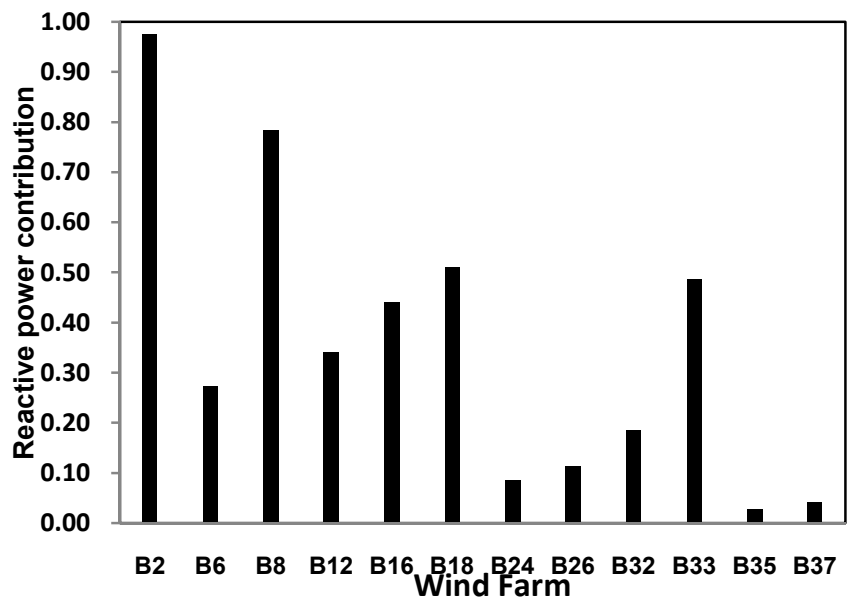

Fig. 5: Reactive power contribution of wind farms for optimization strategy 1
According to Fig. 5, wind farms sited at buses 2, 6, 8, 12, 16,18 and 33 significantly contribute to the system loss minimization. The reactive power contribution from each wind farm for optimization strategy 2 is illustrated in Fig. 6.

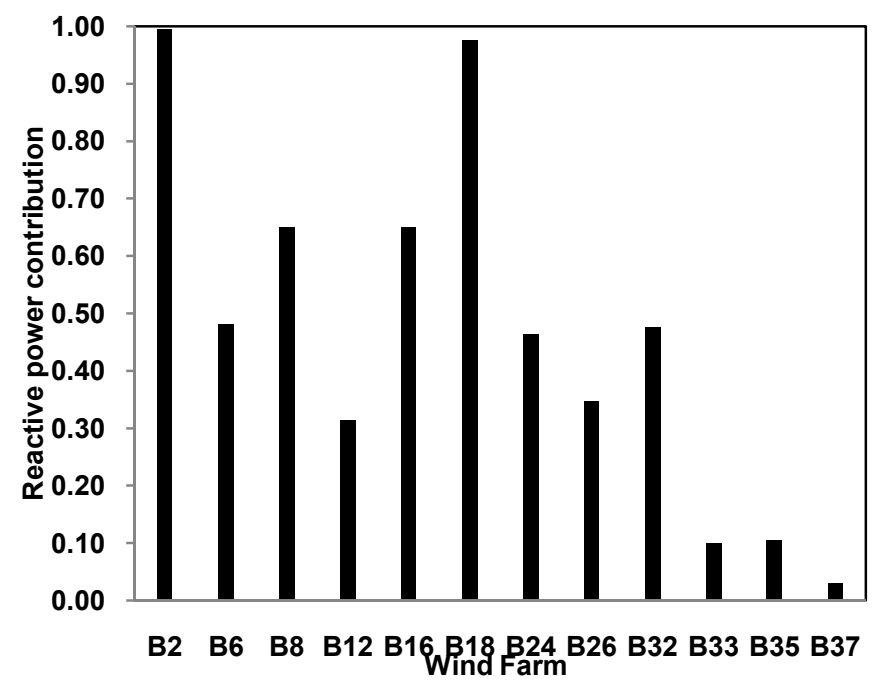

Fig. 6: Reactive power contribution of wind farms for optimization strategy 2

According to Fig. 6, most wind farms increase their reactive power output to maintain the bus voltages at a constant value. This has resulted in an increase in active power losses in the network.

\section{Comparison of Reactive Power Contribution from Wind Farms}

According to the optimization results two distinct wind farm groups can be identified for both voltage stability improvement and loss minimization. Therefore, a significant difference in reactive power output from the wind farms can be observed between both strategies. In particular, the system losses have increased for the voltage control strategy due to reactive power injection / absorption by wind farms to control the terminal voltage. The wind farm reactive power dispatch difference for both strategies as a fraction of the reactive power capability of the DFIG is illustrated in Fig. 7.

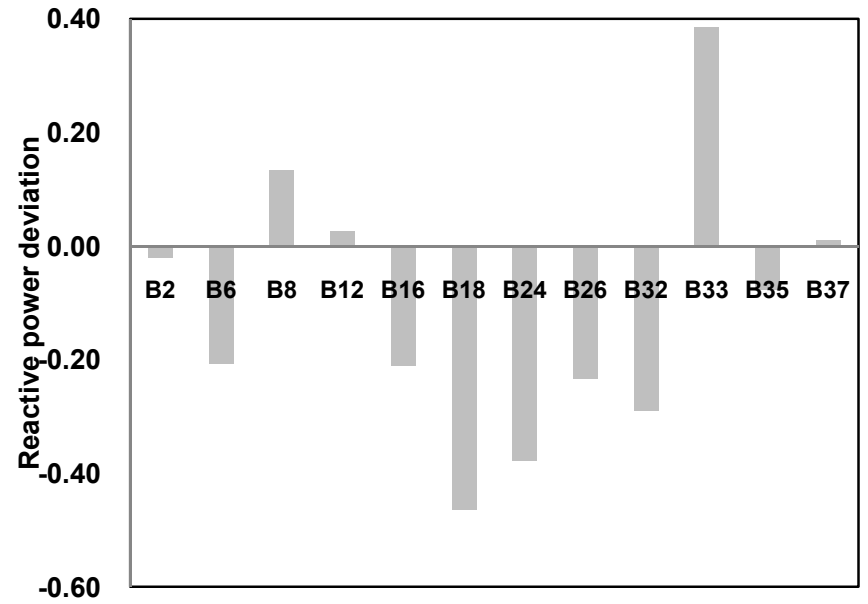

Fig. 7: Reactive power dispatch difference between two optimization strategies

It can be seen that wind farms sited at buses 2, 12, and 37 show an insignificant difference in reactive power dispatch between both strategies while wind farms sited at buses 18 , 
$26,32,6,16,24$ and 33 indicate a reactive power dispatch difference exceeding $20 \%$ of the total reactive power capability. Therefore, in addition to voltage control wind farms some other wind farms also show significant deviation in their reactive power output.

\section{Selective Reactive Power Optimization}

Selective optimization was carried out in order to determine the most critical wind farms for loss minimization. This has been analyzed under two scenarios, considering wind farms for active power loss minimization and voltage security enhancement.

\section{A. Selective Reactive Power Optimization}

In selective optimisation, wind farms were ranked according to their reactive power contribution towards the loss optimization (considering strategy 1 - Fig. 5), applying voltage control for those wind farms contributing most towards loss optimization while operating the remaining wind farms at a fixed power factor. The bus voltages are allowed to vary between $0.95 \mathrm{pu}$ to $1.05 \mathrm{pu}$. The selective optimization scenarios outlined in Table III were carried out for system loss optimization.

\begin{tabular}{c|c}
\multicolumn{2}{c}{ Table III: Wind farms for selective optimization } \\
\hline \hline Optimization Strategy & Wind Farms \\
\hline Selective optimization 6 WFs & $2,18,12,8,16,33$ \\
\hline Selective optimization 4 WFs & $18,2,8,33$ \\
\hline Selective optimization 2 WFs & 2,8 \\
\hline \hline
\end{tabular}

System losses were analyzed by considering the selective optimization scenarios in Table III with the same load demand in the network. Fig. 8 illustrates the system losses for selective optimization under different wind farm loading conditions.

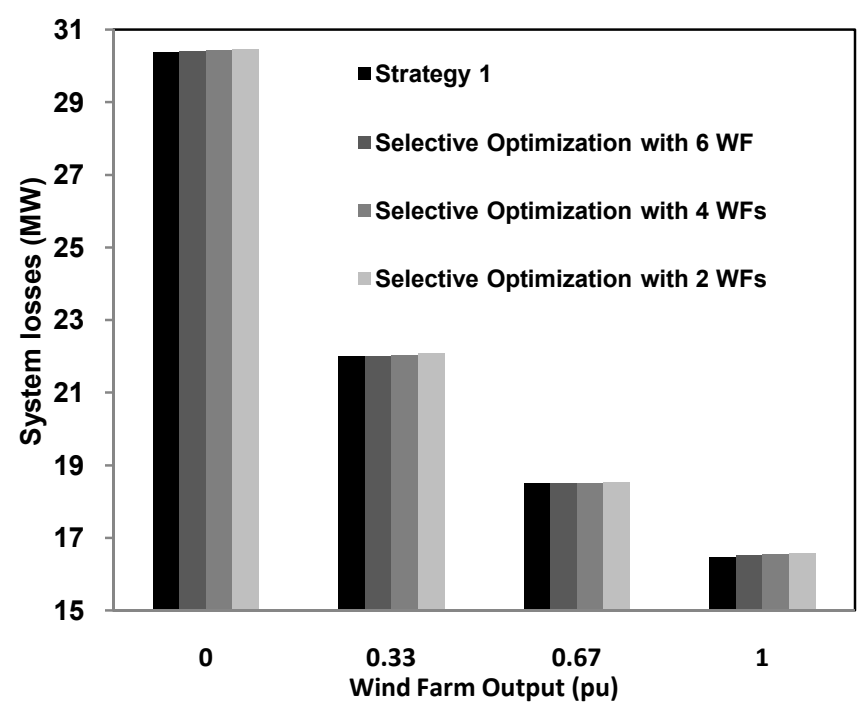

Fig. 8: System losses with selective optimization.

According to Fig. 8, it can be seen that near maximum benefit can be achieved by optimizing the reactive power only at wind farms with a significant contribution towards system loss reduction. As an example, when only two wind farms were optimized for loss reduction the system losses increased by $0.07 \mathrm{MW}$ which represents only a $0.23 \%$ increase compared to strategy 1 . Therefore, selective optimization can reduce the reactive power dispatch burden for the system operator while maintaining the system losses close to the optimal levels.

\section{B. Selective Voltage Control}

In this section, reactive power was optimized while operating only one wind farm in the voltage control mode. Therefore, each individual wind farm in strategy 2 (critical wind farms identified in Fig. 2) was operated in voltage control mode during optimization to analyze the contribution of each wind farm to system losses. Fig. 9 illustrates the average system loss increase from optimal (i.e. from active power losses indicated in OPF strategy 1) when voltage control was implemented at different wind farm locations.

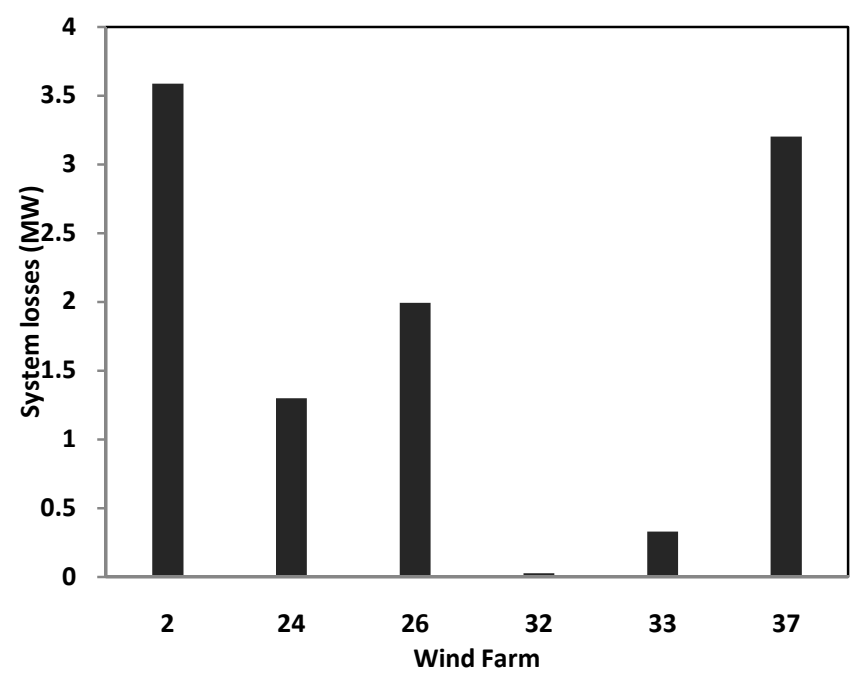

Fig. 9: System loss variation with voltage control at each wind farm location

According to Fig. 9, the maximum deviation occurs when voltage control is implemented at the wind farm at bus 2 . However, when the wind farm at bus 32 is operated in voltage control mode it has the least impact on network losses. The wind farms were then ranked based on their impact towards system optimal losses (i.e. strategy 1 losses) and then voltage control was implemented selectively at the wind farm locations. Fig. 10 illustrates the system losses with selective optimization.

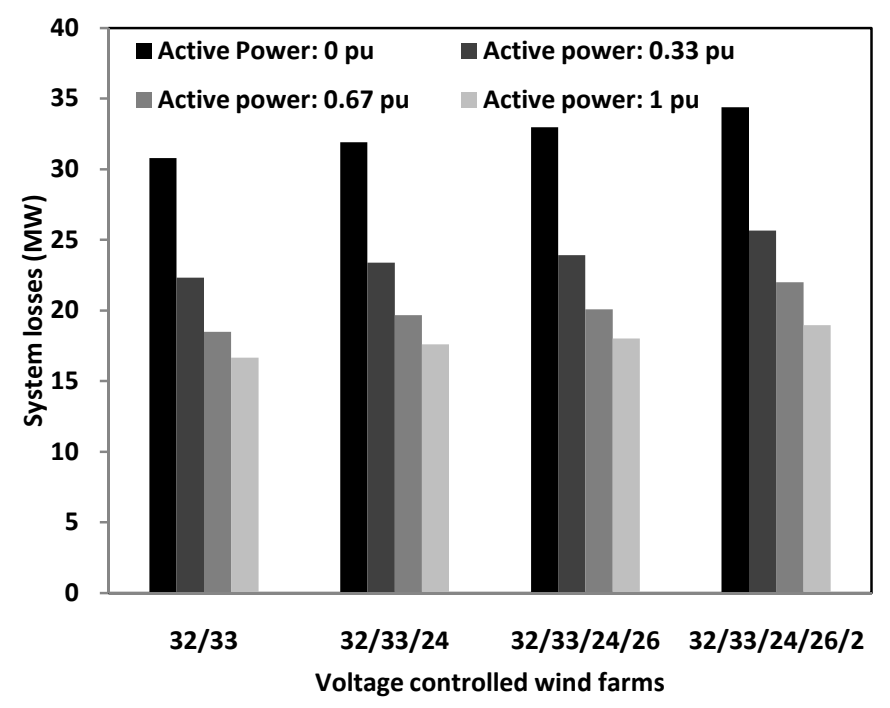

Fig. 10: System losses with selective voltage control 
It can be seen that system losses increase when more and more wind farms are operated in voltage control mode. As an example, at $0 \mathrm{pu}$ active power output, when only two wind farms (e.g. 32 and 33) are operated in voltage control mode the system losses increase by $0.4 \mathrm{MW}$ compared to strategy 1 , however when five wind farms $(32,33,24,26$ and 2) are operated in voltage control mode the system losses have increased by $4 \mathrm{MW}$ compared to strategy 1 .

\section{DISCUSSION}

Traditionally, wind farms are not required to provide ancillary services for network support; hence they do not participate in either voltage control or reactive power provision. However, with the increased penetration levels of wind generation, voltage control and reactive power support have been identified as two necessary requirements for future wind farms. This study has shown that two distinct wind farm categories exist based on their contribution towards voltage stability enhancement and system active power loss minimization. However, certain wind farms have been identified critical for both voltage enhancement and system loss minimization. Therefore, the system operator must determine the tradeoff between two wind farm control strategies based on the network requirements.

\section{CONCLUSIONS}

This study has investigated two reactive power optimization strategies incorporating wind generation. It has illustrated that active power losses increase when wind farms are operated in voltage control mode compared to the optimized reactive power dispatch strategy implemented at all wind farms. The study has further shown that by optimizing the reactive power dispatch only at the most critical (in terms of loss reduction) wind farm locations results in only a marginal increase in active power losses and it is significantly less than the losses incurred during the voltage control mode (strategy 2). Reducing the number of wind farms operating in voltage control mode can reduce the system losses. In particular, by ranking the voltage controlled wind farms based on their individual contribution towards the active power loss increase and by selective operation of wind farms in voltage control mode the system losses can be noticeably reduced. Therefore, the tradeoff between voltage stability improvement and system loss reduction can be achieved by selective operation of wind farms based on their contribution towards loss reduction and voltage stability enhancement.

Further studies are required to analyze the system dynamic performance (i.e. voltage stability and losses) under variable load and wind conditions in order to determine the critical wind farms for different system conditions.

\section{REFERENCES}

[1] L. Meegahapola, S. Durairaj, D. Flynn, and B. Fox, "Coordinated utilisation of wind farm reactive power capability for system loss optimisation," European Transactions of Electrical Power, Vol. 21(1), 2011, pp. 40-51.

[2] R. J. Konopinski, P. Vijayan, V. Ajjarapu, "Extended reactive capability of DFIG wind parks for enhanced system performance," IEEE Trans. Power Syst., vol. 24, no. 3, pp.1346-1355, Aug. 2009.

[3] N. Mo, Z.Y. Zou, K.W. Chan and T.Y.G. Pong, "Transient stability constrained optimal power flow using particle swarm optimisation," IET Gener. Transm. Distrib., 2007, vol. 1, no. 3, pp. 476-483.

[4] R. J. Avalos, C. A. Canizares, and M. F. Anjos, "A practical voltagestability-constrained optimal power flow," IEEE PES GM 2008, Pittsburgh, USA, Jul. 2008.

[5] X. Zhang, R. W. Dunn, and F. Li, "Stability constrained optimal power flow in a practical balancing market," IEEE PES GM 2007, Florida, USA, Jul. 2007.

[6] P. Duttal, and A. K. Sinha, "Voltage stability constrained multiobjective optimal power flow using particle swarm optimization," ICIIS 2006, Sri Lanka, Aug. 2006.

[7] Y. Xu, Z. Y. Dong, K. Meng, J. H. Zhao, and Kit Po Wong, "A hybrid method for transient stability-constrained optimal power flow computation," IEEE Trans. Power Syst. (in press)

[8] W. Rosehart, C. Caiiizares, V. Quintana, "Optimal power flow incorporating voltage collapse constraints," PES Sumer Meeting 1999, Edmonton, Canada, Jul. 1999.

[9] E. Vittal, M. O'Malley, and A. Keane, "A steady-state voltage stability analysis of power systems with high penetrations of wind," IEEE Trans. Power Syst., vol. 25, no. 1, pp. 433-442, Feb. 2010.

[10] Power Factory manual, DIgSILENT Power Factory Version 13.2, GmbH, Germany, 2007.

[11] DSATools User Manual, Powertech Labs Inc., Surrey, British Columbia, Canada

\section{BIOGRAPHIES}

Lasantha Meegahapola is a lecturer in power engineering at University of Wollongong, Australia. He received a BSc. Eng. degree (First Class) from the University of Moratuwa, Sri Lanka in 2006, and a PhD from The Queen's University of Belfast, UK in 2010. His research interests include renewable power generation, power system stability, and intelligent approaches in power systems.

Eknath Vittal received his B.E. from the University of Illinois UrbanaChampaign and his M.S. from Iowa State University in Electrical Engineering in 2005 and 2007 respectively. He completed his Ph.D. at University College Dublin in 2011. He is currently a senior research engineer at University College Dublin with research interests in power systems operation, planning and stability.

Damian Flynn is a senior lecturer in power system operation \& control in the School of Electrical, Electronic \& Communications Engineering, University College Dublin. His research interests involve the integration of renewables into power systems, and advanced modeling and control techniques applied to power plant.

Andrew Keane received B.E. and Ph.D. degrees in Electrical Engineering from University College Dublin in 2003 and 2007 respectively. He is a lecturer with the School of Electrical, Electronic \& Communications Engineering, and University College Dublin with research interests in power systems planning and operation, distributed energy resources and distribution networks. 